\title{
Preliminary Study of Polyacrylonitrile (PAN)/Manganese Oxide Activated Carbon Nanofibers for Cd (II) Adsorption
}

\author{
N. Abdullah ${ }^{1}$, N. Yusof ${ }^{1}$, J. Jaafar $^{1}$, A. F. Ismail ${ }^{1 *}$, F E Che Othman $^{1}$, W. N. W. \\ Salleh $^{1}$, N. Misdan ${ }^{2}$ \\ ${ }^{1}$ Advanced Membrane Technology Centre (AMTEC), Faculty of Chemical and \\ Energy Engineering, Universiti Teknologi Malaysia, 81310 UTM Johor Bahru, Johor, \\ Malaysia \\ ${ }^{2}$ Faculty of Engineering Technology, University Tun Hussien Onn Malaysia, 86400 \\ Parit Raja, Johor, Malaysia
}

\begin{abstract}
In this work, activated carbon nanofibers (ACNFs) from precursor polyacrylnitrile (PAN) and manganese oxide $\left(\mathrm{MnO}_{2}\right)$ were prepared via electrospinning process. The electrospun $\mathrm{PAN} / \mathrm{MnO}_{2}$-based ACNFs were characterized in term of its morphological structure, functional group analysis and specific surface area using SEM-EDX, FTIR and BET analysis respectively. The comparative adsorption study of cadmium (II) ions from aqueous solution between the neat ACNFs, composite ACNFs and commercial granular activated carbon was also conducted. SEM analysis illustrated that composite ACNFs have more compact fibers with presence of $\mathrm{MnO}_{2}$ beads with smaller fiber diameter of $437.2 \mathrm{~nm}$ as compared to the neat ACNFs which is $575.5 \mathrm{~nm}$. BET analysis elucidated specific surface area of ACNFs $/ \mathrm{MnO}_{2}$ to be $67 \mathrm{~m}^{2} / \mathrm{g}$. Under adsorption study, it was found out that Cd (II) removal by ACNFs $/ \mathrm{MnO}_{2}$ was the highest (97\%) followed by neat ACNFs (96\%) and GAC (74\%).
\end{abstract}

Keywords: Activated carbon, Activated carbon nanofiber, Cd adsorption

\subsection{INTRODUCTION}

Water contamination by cadmium has led to numerous studies being conducted for its removal. In general, cadmium $(\mathrm{Cd})$ is categorized as heavy metal that is normally found as ores in other elements and exists in the state of $2+$ in aqueous solution. It is primarily used for metal plating and coating operation, including transportation equipment machinery and baking enamels as well as in nickel-cadmium and solar batteries [1]. The metallurgic industries and mining mentioned earlier serve as anthrophogenic factor for its presence in water. Exposure of cadmium has been profound to be associated with renal damage, osteoporosis, negative bone effects and cancer [2]. Due to that, the maximum contaminant level set by World Health Organization and Environmental Protection Agency (EPA) is 0.005 $\mathrm{mg} / \mathrm{L}[2]$.

Due to hazardous impacts of cadmium exposure, many methods are being employed for its removal such as precipitation, coagulation-flocculation, flotation, ion exchange, membrane filtration and adsorption [3,4]. Among the aforementioned techniques, adsorption has been found to be the most feasible method to eliminate metallic ions imputed by wide range of adsorbents are available, simpler technique and economic [5]. Conventionally, activated carbons (ACs) in powder or granular forms are used as the common materials in

* Corresponding to: A. F. Ismail (email: afauzi@utm.my) 
adsorption method. Recently, application of activated carbon nanofibers (ACNFs) as adsorbents has attracted greater attention due to their excellent adsorption capacities attributed by their smaller fiber diameter, more concentrated pore size distribution. There are several methods can be used to fabricate nanofibers such as melt fibrillation, island-in-sea, and gas jet technique [6]. Nevertheless, it seems that electro-spinning provides more advantages in term of high production rate and relatively low in cost as compared to the other techniques mentioned previously. In addition, ACNFs produced via electrospinning method possess higher specific surface area and better dimensional stability [7].

To prepare electrospun ACNFs, polymer polyacrynitrile serves as a good carbon precursor as it has high carbon yield. Recently, many researches have focused on incorporating various metal oxides such as magnesium oxide, aluminium oxide and manganese oxide into PANbased polymer solution. It is believed that impregnation of metal oxides as additives could increase the specific surface area of ACNFs as well as the pore volume of electrospun ACNFs, attributed by their catalytic activity during pyrolysis process [8]. Therefore, this study aimed to prepare $\mathrm{PAN} / \mathrm{MnO}_{2}$-based ACNFs by the process of electrospinning. The electrospun ACNFs were evaluated in term its morphological changes and its performance towards adsorbing cadmium (II) ions from aqueous solution.

\subsection{MATERIALS AND METHODS}

\subsection{Materials}

Polyacrylonitrile (PAN) with molecular weight of $150 \mathrm{kDa}$ was purchased from Sigma Aldrich (USA). Similarly, N,N-Dimethylformamide (DMF) and manganese (IV) oxide $\left(\mathrm{MnO}_{2}\right)$ powder with $99 \%$ purity were also purchased from Sigma Aldrich (USA). Stock solution of lead ions was prepared using cadmium nitrate (Sigma Aldrich, USA) while $\mathrm{pH}$ of metal solution was adjusted by using $0.01 \mathrm{~mol}$ of $\mathrm{NaOH}$ and $\mathrm{HCl}$ solutions.

\subsection{Preparation of $\mathrm{PAN}-\mathrm{MnO}_{2}$ Nanofiber Mats by Electrospinning}

In brief, dope solution of $\mathrm{PAN}-\mathrm{MnO}_{2}$ was prepared by mixing $2 \mathrm{wt} \%$ of $\mathrm{MnO}_{2}$ (based on total weight of solid) in DMF for 5 hours followed by addition of $10 \mathrm{wt} \%$ PAN. The dope solution was stirred on mechanical stirring plate to obtain suspension with homegeinity. The solution suspension was subsequently fabricated by electrospinning process, under fixed electric field of $15 \mathrm{kV} / 20 \mathrm{~cm}$ and suspension rate of $1.5 \mathrm{~mL} /$ hour. The collected nanofibrous mats were allowed to dry for at least a day prior to carbonization and activation process.

\subsection{Carbonization and Activation of Nanofibers}

The carbonization and activation of electrospun nanofibers were carried by following the procedures described by [9]. The nanofiber mats were initially stabilized in air at $280^{\circ} \mathrm{C}$ for 2 hours, with heating rate of $2^{\circ} \mathrm{C} / \mathrm{min}$ followed by carbonization in nitrogen gas at $600^{\circ} \mathrm{C}$ for 1 hour with heating rate of $5^{\circ} \mathrm{C} / \mathrm{min}$ and lastly heated under carbon dioxide gas at $800^{\circ} \mathrm{C}$ for 3 hours. The 
$\begin{array}{lll}\text { procedures } & \text { of fabricating } & \text { illustrated in Figure } 1 . \\ \text { nanocomposite } & \mathrm{ACNF} / \mathrm{MnO}_{2} \text { is }\end{array}$

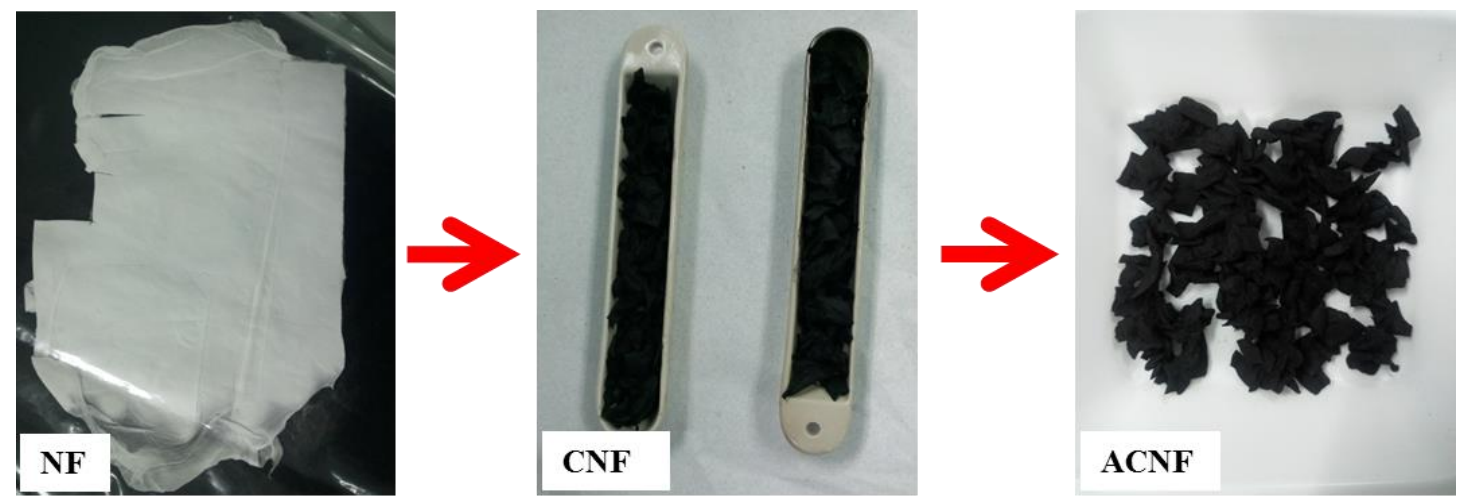

Figure 1 Preparation of nanocomposite ACNFs $/ \mathrm{MnO}_{2}$

\subsection{Characterization}

\subsubsection{Specific Surface Area by BET Analysis}

The specific surface area of prepared nanocomposite nanofibers was determined by $\mathrm{N}_{2}$ adsorption at $130^{\circ} \mathrm{C}$ using automatic Tristar 3000 volumetric system.

\subsubsection{Functional Group Analysis by FTIR Analysis}

The functional groups present in nanocomposite ACNFs were identified using ATR-FTIR spectrometer (Model: IRTRACE100, Shimadzu). The samples were scanned by singlereflectance ATR accessory with IRTRACER100. Each sample had a total of 600 scans at wavelength 500 $\mathrm{cm}^{-1}$ to $4000 \mathrm{~cm}^{-1}$ with scanning resolution of $0.25 \mathrm{~cm}^{-1}$.

\subsubsection{Morphology Studies by SEM- EDS Analysis}

The surface morphologies of nanocomposite and neat ACNFs were examined using Scanning electron microscopy (SEM) (Model: TM 3000, Hitachi). All samples were sputter- coated with platinum to prevent charging, reduce thermal damages and improve electron signal needed for the SEM examination.

\subsection{Sorption Study of Cd(II)}

The adsorptive performance of electrospun nanocomposite ACNFs on $\mathrm{Cd}$ (II) removal was evaluated by conducted a preliminary comparative study between granular activated carbon, neat ACNFs and nanocomposite ACNFs. $0.015 \mathrm{~g}$ of each adsorbent was kept in contact with 15 $\mathrm{mL}$ of $\mathrm{Cd}$ (II) solution on rotary shaker. The solution was agitated for 48 hours at room temperature. The initial $\mathrm{pH}$ was adjusted using $0.01 \mathrm{M}$ $\mathrm{NaOH}$ or $0.01 \mathrm{M} \mathrm{HCl}$. The equilibrium concentration of $\mathrm{Cd}$ was measured by filtering the samples and analyzed using Atomic Absorption Spectrometer (AAS). The removal efficiency ( $\%$ ) of $\mathrm{Cd}$ (II) was calculated using: $\left(\mathrm{C}_{0^{-}}\right.$ $\left.\mathrm{C}_{\mathrm{e}}\right) / \mathrm{C}_{\mathrm{o}} \times 100$, where $C_{o}$ and $C_{e}$ are initial concentration and equilibrium concentration $(\mathrm{mg} / \mathrm{L})$ of metal, respectively. 


\subsection{Desorption of $\mathrm{ACNFs} / \mathrm{MnO}_{2}$ Activated Nanofibers}

Desorption of $\mathrm{ACNFs} / \mathrm{MnO}_{2}$ used in this study was performed to identify its recovery rate. The $A C N F s / \mathrm{MnO}_{2}$ used for batch adsorption study was rinsed with distilled water to eliminate any residual solutions and subsequently dried in oven at room temperature. Desorption of metal ions were carried out by immersing the samples in $1 \mathrm{M}$ $\mathrm{HCl}$ and agitated at $30^{\circ} \mathrm{C}$ with speed of $100 \mathrm{rpm}$ for 1 hour. The concentration of $\mathrm{Cd}$ ions in the solution was analyzed using atomic absorption spectrometer (AAS) and the desorption ratio (D, \%) was calculated as follows: (amount of metal desorbed (mg)/ amount of metal ion adsorbed into $\left.\mathrm{ACNFs} / \mathrm{MnO}_{2}\right) \mathrm{x}$ 100.

\subsection{RESULTS AND DISCUSSION}

\subsection{Characterization Nanocomposite ACNFs}

\subsubsection{Specific Surface Area}

The effects of activation on specific surface area of ACNFs are depicted in Table 1. From the table, it is evident that the process of activation improved the pore volume of ACNFs and eventually increased the specific surface area from $478.2298 \mathrm{~m}^{2} / \mathrm{g}$ (neat ACNFs $)$ to $599.4 \quad \mathrm{~m}^{2} / \mathrm{g}($ ACNFs/ $/ \mathrm{MNO}_{2}$ ). Table 2 tabulates the pore size, and total pore volume of prepared neat and nanocomposite ACNFs. It is revealed that addition of $\mathrm{MnO}_{2}$ led to larger pore size $(0.25514$ $\mathrm{cm} 3 / \mathrm{g}$ ) and higher total pore volume $(0.298648 \mathrm{~cm} 3 / \mathrm{g})$ as compared to the neat ACNFs. The higher specific surface area, larger pore size and higher total pore volume can be described by two mechanisms; 1) physical phenomena where $\mathrm{MnO}_{2}$ particles migrated and thus created pore channels, and 2) role of $\mathrm{MnO}$ as catalyst that accelerate the activation rate and thus causing formation of higher amount of pores [8].

Table 1 Effect of activation on SSA of nanofiber mats

\begin{tabular}{|c|c|c|}
\hline \multirow[t]{2}{*}{ Sample } & \multicolumn{2}{|c|}{$\begin{array}{l}\text { Specific surface area } \\
\quad(\text { S.S.A })\left(\mathrm{mg}^{2} / \mathrm{g}\right)\end{array}$} \\
\hline & $\begin{array}{c}\text { Before } \\
\text { activation }\end{array}$ & $\begin{array}{c}\text { After } \\
\text { activation }\end{array}$ \\
\hline $\begin{array}{l}\text { Neat } \\
\text { ACNFs }\end{array}$ & 9.13 & 478.2298 \\
\hline $\begin{array}{l}\mathrm{ACNFs} / \\
\mathrm{MnO}_{2}\end{array}$ & 12.45 & 599.4 \\
\hline
\end{tabular}

Table 2 BET multiple point analysis

\begin{tabular}{cccc}
\hline & $\begin{array}{c}\text { S.S.A } \\
\left(\mathbf{m}^{2} / \mathbf{g}\right)\end{array}$ & $\begin{array}{c}\text { Pore } \\
\text { size } \\
\left(\mathbf{c m}^{3} / \mathbf{g}\right)\end{array}$ & $\begin{array}{c}\text { T.P.V } \\
\left(\mathbf{c m}^{3} / \mathbf{g}\right)\end{array}$ \\
\hline ACNFs & 478.2 & 0.19389 & 0.20967 \\
ACNFs/ & 599.4 & 0.28514 & 0.29864 \\
MnO2 & & & \\
\hline
\end{tabular}

\subsubsection{Functional Group Analysis}

The FTIR spectrum of $\mathrm{ACNF} / \mathrm{MnO} 2$ is shown in Figure 2. It can be seen that activation process removed nitrile groups $(\mathrm{C} \equiv \mathrm{N})$ and methylene group $\left(\mathrm{CH}_{2}\right)$. The absorption peaks at 1097.5 $\mathrm{cm}^{-1}, \quad 1801.5 \mathrm{~cm}^{-1}, \quad 1990.54 \mathrm{~cm}^{-1}$, $2113.98 \mathrm{~cm}^{-1}$ and $2326.15 \mathrm{~cm}^{-1}$ representing $\mathrm{C}-\mathrm{O}, \mathrm{CH}_{2}, \mathrm{C}=\mathrm{O}$, and $\mathrm{C}=\mathrm{C}$ groups, respectively. Meanwhile, absorption peak at $528.5 \mathrm{~cm}^{-1}$ was identified as $\mathrm{Mn}-\mathrm{O}$, indicating the presence of $\mathrm{MnO}_{2}$ in the ACNFs. 


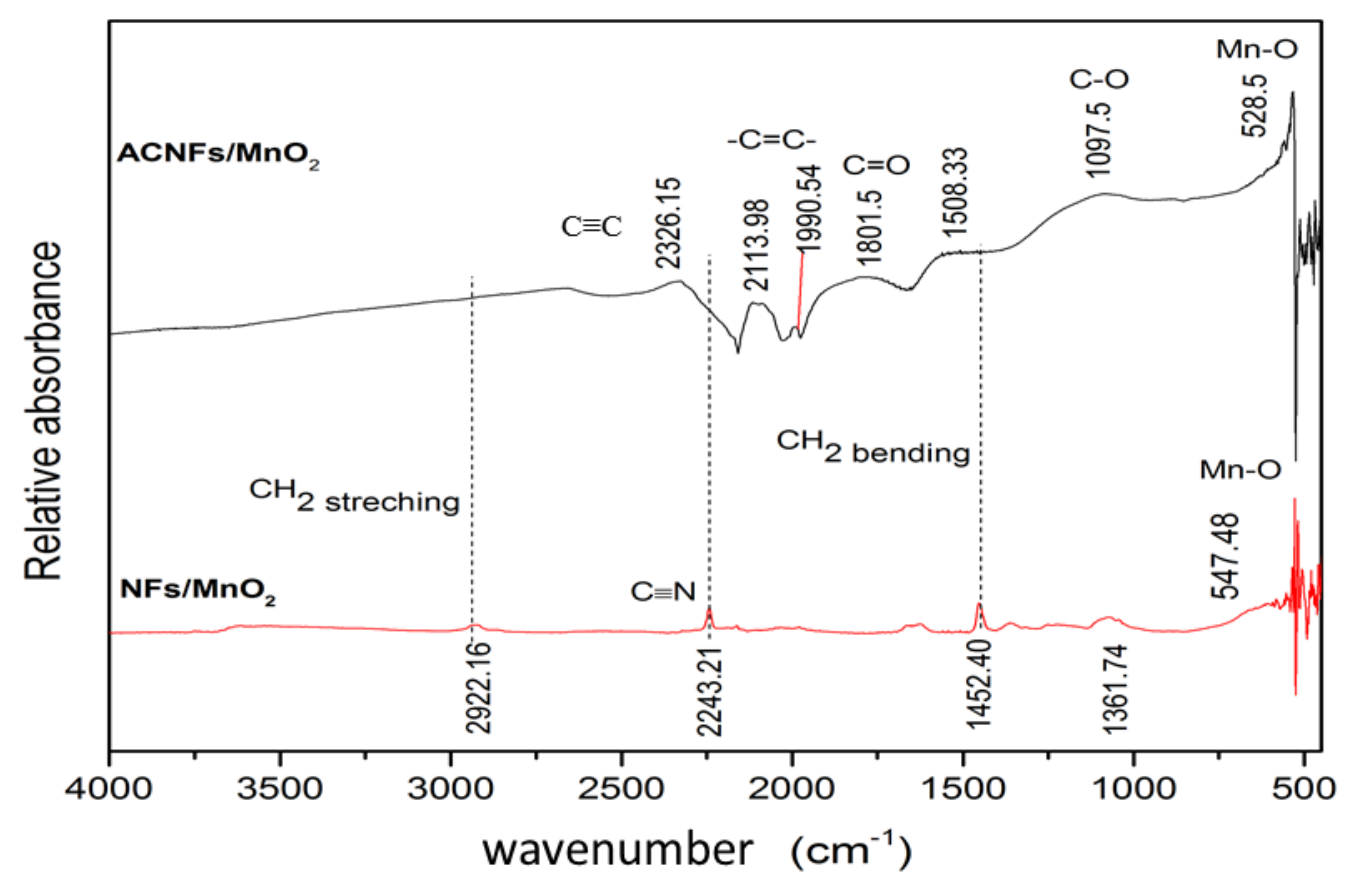

Figure 2 Functional group analysis of neat ACNFs and nanocomposite ACNFs

\subsubsection{Scanning Electron Microscopy (SEM)}

Figure 3 exhibits the SEM micrograph images of neat ACNFs and $\mathrm{ACNF} / \mathrm{MnO}_{2}$. It can be observed that neat ACNFs possessed more aligned nanofibers while $\mathrm{ACNFs} / \mathrm{MnO}_{2}$ showed more compact arrangement with rougher and bent surfaces. When comparing the diameter of ACNFs without and with $\mathrm{MnO}_{2}$, it is revealed that ACNFs embedded with $\mathrm{MnO}_{2}$ attained smaller diameter in the range of $433.7 \mathrm{~nm}$ while neat ACNFs possessed fibers with larger diameter of $669.0 \mathrm{~nm}$. It should be noted that $\mathrm{MnO}_{2}$ may dispersed as beads located in the outer side of ACNFs as denoted by arrow in (bi). The morphology of electrospun ACNFs obtained in this study is concurring to the study conducted by [10] in which the $\mathrm{ACNF} / \mathrm{MnO}_{2}$ was observed to have compact nanofibers with dispersion of beads containing $\mathrm{MnO}_{2}$ particles. This observation was further supported by EDX mapping, as depicted in Figure 4. It is presumed that during electrospinning process, there was jet instability occurred in which polymeric PAN solution was ejected first, followed by sputtering of $\mathrm{MnO} 2$ particles [11]. Nevertheless, EDXmapping analysis indicated the dispersion of $\mathrm{MnO}_{2}$ is rather homogenous, despite of the formation of $\mathrm{MnO}_{2}$-contained beads alongside the nanofibers. 

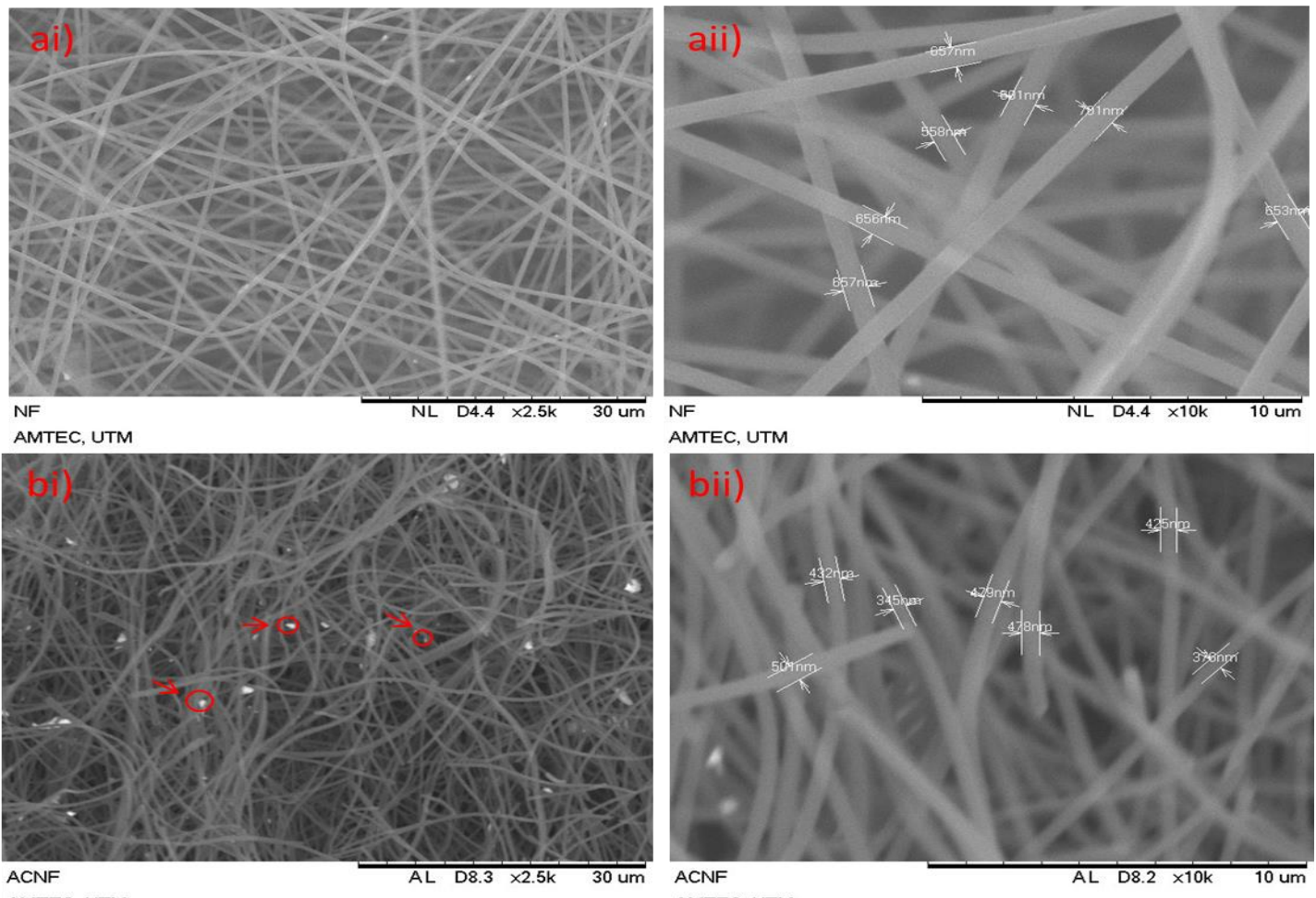

AMTEC, UTM

AMTEC, UTM

Figure 3 SEM micrograph analysis of a) neat ACNF, b)ACNFs $/ \mathrm{MnO}_{2}$ where i) 2500x magnification and ii) $10000 \mathrm{x}$ magnification
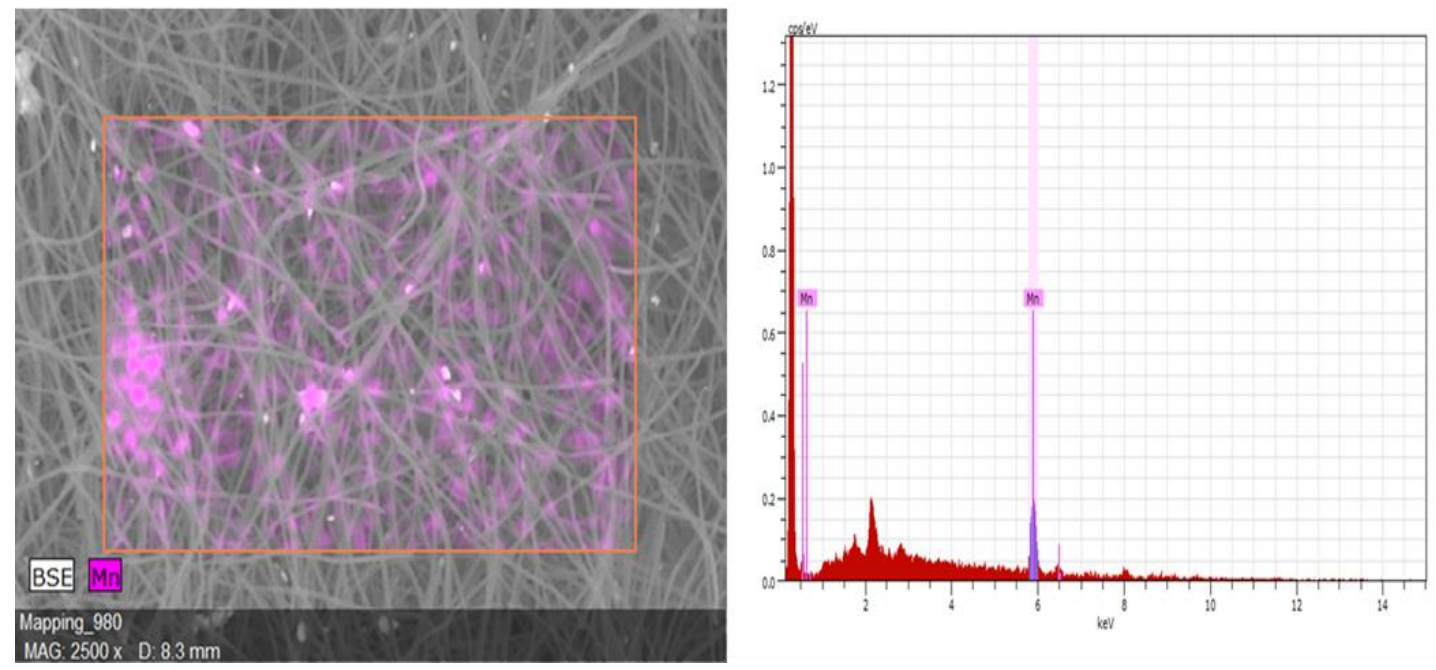

Figure 4 EDX mapping of Mn on ACNFs 


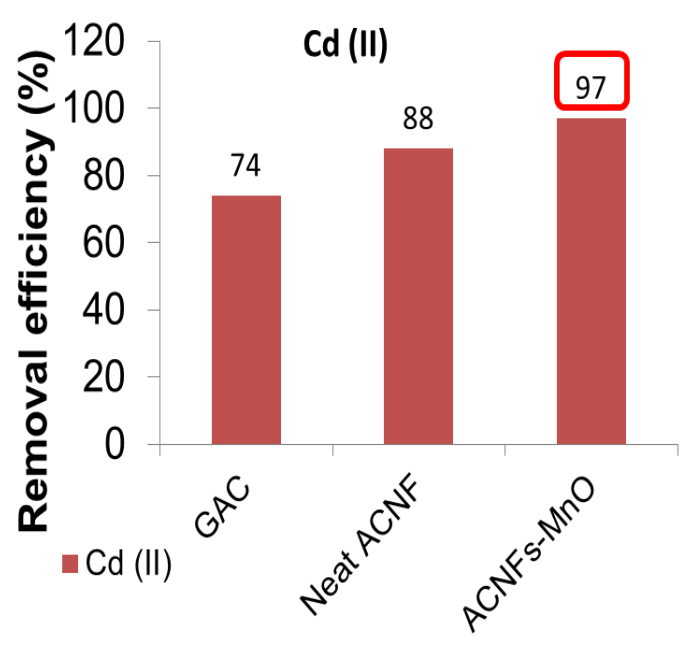

Figure 5 Comparative study of removal of Cd (II) ions by granular activated carbon (GAC), neat ACNFs and ACNFs/ $\mathrm{MnO}_{2}$. Operating conditions: dose $=1 \mathrm{~g} / \mathrm{L}$ ' stirring speed $=180 \mathrm{rpm}$, temperature $=$ room temperature, and contact time $=48$ hours.

Figure 5 illustrates the comparative adsorption study of Cd (II) by granular activated carbon, pure ACNFs and $\mathrm{ACNFs} / \mathrm{MnO}_{2}$. From the figure, it can be seen that highest removal of Cd (II) was achieved when composite ACNFs/ $/ \mathrm{MnO}_{2}$ was used as adsorbent in the solution which is $97 \%$ followed neat ACNFs (88\%) while adsorption by GAC illustrated lower removal efficiency which is $74 \%$. Hence, the order of performance is: $\mathrm{ACNF} / \mathrm{MnO}_{2}$ $>$ ACNFs $>$ GAC. In theory, the removal capability can be linked to the SSA where more active adsorption sites are available. In addition, the adsorption capacity may also attributable to the amount of surface total acidity present on the surface of ACNFs/ $\mathrm{MnO}_{2}$. Based on this statement, it can be depicted that the adsorption of $\mathrm{Cd}$ (II) ions onto ACNFs occur by means of chemisorption where it is mainly controlled by the strong interaction between Cd (II) ions and surface functional groups such as carboxyl and hydroxyl [12,13]
As depicted by Figure 2, there are five major peaks observed located at $2326.15 \mathrm{~cm}^{-1}, 2113.98 \mathrm{~cm}^{-1}, 1990.54$ $\mathrm{cm}^{-1}, 1801.51 \mathrm{~cm}^{-1}$ and $1097.50 \mathrm{~cm}^{-1}$. The peak $2326.15 \mathrm{~cm}^{-1}$ is assigned as $\mathrm{O}-\mathrm{H}$ stretch from strongly hydrogenbonded $-\mathrm{COOH}$. Peaks 2113.98 and $1990.54 \mathrm{~cm}^{-1}$ basically attributed to the strong stretching of $\mathrm{C}=\mathrm{C}$ groups and peak 1801.51 and 1097.50 indicated as stretching vibrations of $\mathrm{C}-\mathrm{O}$ groups. These detected functional groups may play role for adsorption of Cd (II). In addition, the mechanism of chemisorption can basically confirmed by testing two common sorption models which are Langmuir model and Freundlich model based on their respective equations, and evaluation of their regression value (not performed in this study) [14]. It is also demonstrated that the adsorption capacity of composite ACNFs used in this study is $6.1 \mathrm{mg} / \mathrm{g}$ that is higher as compared to the commercial GAC (4.6 $\mathrm{mg} / \mathrm{g}$ ). The higher adsorption capacity can be explained by the role of manganese oxide itself that functions as an adsorbent and it has higher affinity towards metallic ions [11].

For desorption study, it was found out that ACNFs used in this study has higher regeneration rate which was more than $95 \%$. This high reusability exhibits its potential as another promising adsorbent for heavy metal adsorption.

\subsection{CONCLUSION}

This present study reports the preparation of ACNFs/manganese oxide by electrospinning process for removal of cadmium (II) ions from aqueous solution. In this study, ACNFs shows promising adsorption capacity upon adsorbing $\mathrm{Cd}$ (II) as compared to the commercial GAC. The ACNFs incorporated by $\mathrm{MnO}_{2}$ has found to be 
more compact and possessed smaller diameter as compared to the neat ACNFs. In this study, the adsorption process is believed to occur by means of chemisorption that involves the interaction of $\mathrm{Cd}$ (II) ions with surface functional groups, regardless of their low specific surface area. The sorption/desorption study indicates the excellent reusability of this new type of activated carbon. Further research on exploring more potential of these ACNFs is recommended.

\section{ACKNOWLEDGEMENT}

The authors would like to acknowledge the financial support from Malaysian Ministry of Education and Universiti Teknologi Malaysia under Grant No. R.J130000.7842.4F279 and Q.J130000.2542.05H46. The authors would also like to acknowledge the technical and management support from Research Management Centre (RMC), Universiti Teknologi Malaysia.

\section{REFERENCES}

[1] Y. H. Li, S. Wang, Z. Luan, J. Ding, C. Xu, D. Wu. 2003. Adsorption Of Cadmium(II) From Aqueous Solution By Surface Oxidized Carbon Nanotubes. Carbon. 41: 10571062.

[2] M. Khairy, S. A. El-Safty, M. Shenashen. 2014. Environmental Remediation And Monitoring Of Cadmium. Trends Anal. Chem. 62: 56-68.

[3] K. S. Rao, M. Mohapatra, S. Anand, P. Venkateswarlu. 2010. Review On Cadmium Removal From Aqueous Solutions. Envi.Chem. Lett. 2: 1-103.

[4] M. Barakat. 2011. New Trends
In Removing Heavy Metals From Industrial Wastewater. Arab. J. Chem. 4: 361-377.

[5] S. Dadvar, H. Tavanai, M. Morshed, M. Ghiaci. 2013. A study On The Kinetics Of 2Chloroethyl Ethyl Sulfide Adsorption Onto Nanocomposite Activated Carbon Nanofibers Containing Metal Oxide Nanoparticles. Sep. Purif. Technol. 114: 24-30.

[6] S. Ramakrishna, K. Fujihara, W.E. Teo, T. Yong, Z. Ma, R. Ramaseshan. 2006. Electrospun nanofibers: Solving Global Issues. Mater. Today. 9: 40-50.

[7] G. Oh, Y. Ju, H. Jung, W. Lee. 2008. Preparation Of The Novel Manganese-Embedded PANBased Activated Carbon Nanofibers By Electrospinning And Their Toluene Adsorption. J.Anal.Appl.Pyrolysis. 81: 211217.

[8] S. Dadvar, H. Tavanai, M. Morshed. 2012. Journal Of Analytical And Applied Pyrolysis Effect Of Embedding Mgo And $\mathrm{Al}_{2} \mathrm{O}_{3}$ Nanoparticles In The Precursor On The Pore Characteristics Of PAN Based Activated Carbon Nanofibers. $J$. Anal. Appl. Pyrolysis. 98: 98105. d.

[9] N. Yusof, A. F. Ismail. 2012. Post spinning And Pyrolysis Processes Of Polyacrylonitrile ( PAN ) -Based Carbon Fiber And Activated Carbon Fiber: A Review. J. Anal. Appl. Pyrolysis. 93: 1-13.

[10] J. Zhang, J. Jiang, X. S. Zhao. 2011. Synthesis and Capacitive Properties of Manganese Oxide Nanosheets Dispersed on Functionalized Graphene Sheets. J. Phys. Chem. 115: 6448-6454.

[11] S. K. Nataraj, K. S. Yang, T. M. Aminabhavi.

2012. 
Polyacrylonitrile-Based

Nanofibers-A State-Of-The-Art Review. Prog. Polym. Sci. 37: 487-513.

[12] R. A. Khalkhali, R. Omidvari,. 2005. Adsorption of Mercuric Ion from Aqueous Solutions Using Activated Carbon. Polish J. Environ. Stud. 14: 185-188.

[13] A. Gadhave, J. Waghmare. 2014. Removal Of Heavy Metal Ions From Wastewater By Carbon
Nanotubes (Cnts). Int. J. Eng. Sci. Res. Technol. 3: 226-236.

[14] P. Kampalanonwat, P. Supaphol. 2010. Preparation And Adsorption Behavior Of Aminated Electrospun Polyacrylonitrile Nanofiber Mats For Heavy Metal Ion Removal. ACS Appl. Mater. Interfaces. 2: 3619-3627. 